\title{
The Impact of Industrial Agglomeration on the FDI Location
}

\author{
Selection \\ Shuhui Zuo, Fang Sun * \\ Nanjing University of Science and Technology, China \\ *Corresponding author: Sun fang, associate professor, Nanjing University of Science and \\ Technology, sunfang28@hotmail.com
}

\begin{abstract}
Since the reform and opening up, the main factors that affect the multinational corporations' location choice in making direct investment in China have been evolving. In mid and late 1990s, industrial agglomeration has become an important influence factor. In this paper, we will base on the framework of industrial agglomeration theory, the traditional investment theory, and use multiple linear regression model to analyze the factors on the choice of location of foreign direct investment. It is found that the industrial agglomeration has replaced the traditional location selection factors as an important force to influence the investment decisions of multinational corporations.
\end{abstract}

Keywords: industrial agglomeration; foreign direct investment; location choice

\section{Introduction}

With the deepening of world economic liberalization and integration, the multinational corporation has become the most important organizational forms of international economic activities, which break through the narrow geographical restrictions and facilitate direct investment or subsidiary establishment in the global scope. The expansion of multinational corporations have greatly influenced the world economy. Therefore, it is very necessary to study the factors that influence the location choice of FDI. In recent years, with the continuous development of industrial agglomeration, FDI also shows a relatively concentrated trend. The purpose of this study is to explore the influence of FDI location choice factors under the background of rapidly developing industrial agglomeration situation. The study attempts to provide a theoretical basis for the Chinese foreign investment policies.

\section{Related theory and literature review}

\subsection{Related theories on industrial agglomeration}

The industrial agglomeration refers to the high concentration of the same industry in a particular geographical region. And industrial capital elements have a process of constant convergence in the space. From an international perspective, the industrial agglomeration is a common phenomenon in the process of industrialization, and it is one route to develop the 
competitiveness of the developed countries.

The overseas research about industrial agglomeration focuses on the following aspects: mechanism of the industrial agglomeration, technological innovation, organizational innovation, social capital, the relationship between economic growth and industrial agglomeration, industrial agglomeration and the industrial development policy.OECD ${ }^{1}$ has made an empirical analysis on the industrial agglomeration of different countries and raised the question on how to make the industrial agglomeration more competitive.

Research in China on industrial agglomeration began in the 1990s. The research includes three categories: review of the overseas research results of industrial agglomeration; discussions on the theory of the industrial agglomeration formation mechanism, dynamic mechanism and other issues; comparative studies of the classification of industrial agglomeration. Zhu Yingming ${ }^{2}$ conducts a system analysis and application analysis of industrial clusters, connects the industrial clusters with regional development and innovation learning, reveals the logical relationship of industry cluster and competitiveness and regional development strategy and suggested measures to promote the development of industrial clusters.

\subsection{FDI location choice theory}

There are three major theories on location choice of FDI. The first theory is monopolistic advantage theory which holds that an important reason for the multinational corporations' FDI decision is non- exclusive external market structure. This enables the enterprise to maintain a specific advantage and offsets the unfavorable factors for the host country and the local enterprise.

The second theory is the market internalization theory proposed by Casson, Buckley et al. ${ }^{3}$ They point out that, as long as the cost of the resources allocation in the market is lower than the use market in a certain region, there will be multinational enterprises. And they stress that the essence of internalization refers to the process of establishing the market in the company, using internal market to replace the original fixed external market. The theories involve the causes for multinational corporations to make direct investment and the basic conditions of direct investment, but they do not consider the location choice for FDI.

The third theory is the international production compromise theory established by Dunning ${ }^{4}$ in 1976. Its core content is the OIL model, that is, only if the enterprises have the ownership advantage, the advantage of internalization and location advantage, they will choose FDI. The theory can explain the problem of FDI location choice, but it does not distinguish the relationship between the three advantages.

\section{Variable analysis}

From the perspective of the agglomeration advantage , Weber thinks, the agglomeration offers agglomeration advantage on location choice of multinational companies, thus enhancing the 
overall competitive advantage. Some other advantages of industrial agglomeration include social network advantage, scale economy advantage and technological innovation advantage. From the view of agglomeration effect,the effect of industrial agglomeration is reflected in three aspects: urbanization agglomeration effect, agglomeration effect on specific industries and the demonstration effect on transnational direct investment.

In summary, combined with the previous studies, the factors that affect the location selection of FDI in the context of industrial agglomeration are summarized as follows:

1 POL: Regional preferential policy index embodies the preferential tax and credit in each region, relaxation of import and export rights and the use of foreign concessions, the implementation of these policies is mainly reflected through the establishment of special economic zones in the region, high-tech development zones, coastal open city strategies. Therefore, the special economic zone established in our country is chosen as the proxy variable. The weight value varies with degrees of preferential policies in different regions, 2 OPEN: Regional opening index reflects the relationship between the local economy and the external economy . The OPEN index is represented by the degree of dependence on foreign trade, i.e. the proportion of total imports and exports in each region to its gross national product)

3 BASE: Regional infrastructure index reflects the development level of regional infrastructure. Infrastructure includes transportation, communications, water supply, education, health care, etc.It is an important factor that affects the location choice of FDI.

4 AGDP: Regional Gross National Product reflects the size of the market size of the region. AGDP index is an important indicator of the overall level of economic development. Domestic and foreign index system are selected and placed in the core position.

5 QY: QY refers to the number of industrial enterprises in the region. The most marked feature of the industrial agglomeration is that the number of enterprises is concentrated in space. The number of enterprises is an effective indicator to measure the concentration degree of industrial production activities. Because the data of the enterprises in various regions lacks, this paper uses "all state-owned and non state-owned industrial enterprises" instead in the research.

6 SERV: Business services level index uses the ratio of GDP in the region. The degree of business services agglomeration in urban areas is also very important to attract FDI, in addition to basic infrastructure conditions, foreign investors will also have a certain degree of requirements to the level of business services. Well-developed transportation and warehousing and post and telecommunications industries should have a positive effect.

7 FDIt: FDIt represents lag phase variable of FDI. Studies have shown that the early stage of FDI activities is often caused by the downstream and related industries to invest through the demonstration and emulation effects, and then leads into the next phase of establishing supporting enterprises and increasing direct investment in China, FDI has a "demonstration effect". 
8 INNO: Knowledge innovation index. The Index uses three kinds of number of patent applications and the number of authorized.

The above variables are expected to have a positive effect on FDI.

\section{Empirical analysis}

\subsection{Mathematical formulas and equations}

In this paper, we use the multiple linear regression model to test data to find out the factors that influence the location choice of FDI. The model is constructed as follows:

$$
\begin{gathered}
\ln F D I_{i}=\varepsilon+\beta_{1} \mathrm{OPEN}_{\mathrm{i}}+\beta_{2} \mathrm{BASE}_{\mathrm{i}}+\beta_{3} \ln A G D P_{i}+\beta_{4} \ln Q Y_{i}+\beta_{5} \mathrm{SERV}_{\mathrm{i}}+ \\
\beta_{6} \mathrm{INNO}_{\mathrm{i}}+\beta_{7} \mathrm{FDIt}_{i}+\beta_{8} \mathrm{POL}_{\mathrm{i}}+\mu
\end{gathered}
$$

Among them, letter i represents the ith observation values.

We use Eviews runs data and have the results as shown in Fig. 1. It can be seen that the degree of regional openness OPEN, the number of industrial enterprises in the region QY, FDI lag time variable FDIt have a significant positive effect on the FDI traffic, both at significant level of 5\%. The regional innovation index INNO and the traditional direct investment location variable region infrastructure BASE, regional preferential policies FDI POL traffic have a significant reverse effect, which is not consistent with expectations. Regional market size of the reaction area AGDP and regional service development level of FDI on the impact of SERV traffic are not significant.

\begin{tabular}{crrrr}
\hline \hline Variable & Coefficient & Std. Error & t-Statistic & Prob. \\
\hline \hline C & 29.77653 & 23.48679 & 1.267799 & 0.2256 \\
OPEN & 72.18947 & 21.76056 & 3.317446 & 0.0051 \\
BASE & -218.5629 & 97.89585 & -2.232606 & 0.0424 \\
AGDP & -0.002460 & 0.002987 & -0.823586 & 0.4240 \\
QY & 0.001972 & 0.000740 & 2.665131 & 0.0185 \\
SERV & -21.88668 & 55.14151 & -0.396918 & 0.6974 \\
FDIT & 0.916170 & 0.042598 & 21.50728 & 0.0000 \\
INNO & -0.000259 & $6.82 \mathrm{E}-05$ & -3.795382 & 0.0020 \\
POL & -8.385217 & 3.755735 & -2.232643 & 0.0424 \\
\hline R-squared & 0.988654 & Mean dependent var & 112.7396 \\
Adjusted R-squared & 0.982170 & S.D. dependent var & 82.33070 \\
S.E. of regression & 10.99360 & Akaike info criterion & 7.918675 \\
Sum squared resid & 1692.028 & Schwarz criterion & 8.362999 \\
Log likelihood & -82.06476 & Hannan-Quinn criter. & 8.030421 \\
F-statistic & 152.4828 & Durbin-Watson stat & 1.891167 \\
Prob(F-statistic) & 0.000000 & & & \\
\hline \hline
\end{tabular}

Fig. 1 - Eviews results (1)

According to the results of the first step regression, excluding two non-significant variables which continue to carry out regression analysis, the results are as shown in Fig. 2.

$$
\ln F D I_{i}=\varepsilon+\beta_{1} \mathrm{OPEN}_{\mathrm{i}}+\beta_{2} \mathrm{BASE}_{\mathrm{i}}+\beta_{3} \ln Q Y_{i}+\beta_{4} \mathrm{INNO}_{\mathrm{i}}+\beta_{5} \mathrm{FDIt}_{i}+\beta_{6} \mathrm{POL}_{\mathrm{i}}+\mu
$$

We can see that the significance of the remaining variables is improved. Regional openness OPEN, the number of industrial enterprises in the region QY, FDI lag phase variable FDIt, regional innovation index INNO and other variables of the significant level in 1\%; regional infrastructure BASE, regional preferential policies POL significant level in 5\%. The fitting degree of the model is very good from the adjusted coefficient of 0.983475 . 


\begin{tabular}{crrrr}
\hline \multicolumn{6}{l}{ Inciudea odservations: Z3 } \\
\hline \hline Variable & Coefficient & Std. Error & t-Statistic & Prob. \\
\hline \hline C & 17.09948 & 6.693663 & 2.554577 & 0.0212 \\
OPEN & 62.69067 & 16.15023 & 3.881719 & 0.0013 \\
BASE & -213.6698 & 93.22046 & -2.292091 & 0.0358 \\
QY & 0.001570 & 0.000417 & 3.766231 & 0.0017 \\
FDIT & 0.909524 & 0.039685 & 22.91832 & 0.0000 \\
INNO & -0.000255 & $6.25 E-05$ & -4.078977 & 0.0009 \\
POL & -7.390265 & 3.453897 & -2.139689 & 0.0481 \\
\hline R-squared & 0.987982 & Mean dependent var & 112.7396 \\
Adjusted R-squared & 0.983475 & S.D. dependent var & 82.33070 \\
S.E. of regression & 10.58343 & Akaike info criterion & 7.802246 \\
Sum squared resid & 1792.143 & Schwarz criterion & 8.147831 \\
Log likelihood & -82.72583 & Hannan-Quinn criter. & 7.889160 \\
F-statistic & 219.2257 & Durbin-Watson stat & 1.969705 \\
Prob(F-statistic) & 0.000000 & & & \\
\hline \hline
\end{tabular}

Fig. 2 - Eviews results (2)

\subsection{Results and Discussion}

From the regression results, we can find that the impact of agglomeration factors on FDI has gradually replaced the traditional direct investment location factors, and has become an important variable in recent years. The number of QY reaction of industrial enterprises in the region has a significant positive effect on the two test models. The removal of the non significant factors can pass the test at the $1 \%$ significance level. The number of industrial enterprises directly reflects the regional industrial agglomeration, which can explain the industrial agglomeration effect on the location of foreign direct investment. That is confirmed in the camphor type which is consistent with expectations.

FDIt which reflects the FDI "demonstration effect" has a very high level of significance, the results of the second test FDIt coefficient of 0.91 shows that the early FDI each increase of $1 \%$, will result in the latter period of FDI increase by $0.91 \%$. This shows that early FDI enterprises are often caused by the downstream and related industries to invest through the demonstration effect and promoting effect, and then led into the next phase of supporting enterprises, increase direct investment in China, this verifies the existence of FDI "demonstration effect".

The first test results show that the tertiary sector in the variable value of SERV of the city's GDP is negative, and the test coefficient is not significant, which shows that the tertiary has almost no impact on the FDI. According to the previous hypothesis, because many segments of the economy belong to the tertiary sector, SERV coefficient should be significant, but the empirical result is not the case. In addition to statistical caliber factors, this may be explained by imperfection in China's tertiary sector, which has yet to be fully developed and the effects on FDI are not fully displayed.

Variable OPEN that reflects the degree of openness of the local area passes the significance test. The foreign capital enterprise of our country is an important element of China's import and export value. So for those processing export-oriented enterprises, the degree of openness is an important factor affecting their location choice.

In the traditional direct investment location choice theory, the market size of GDP has no 
significant effect on the FDI. This shows that with the rapid development of China's economy savings increase at the same time because people are more inclined to save. Consumption tends to start with the increase in revenue narrows, the market potential start to shrink. This also explains foreign investors do not consider the market size when making direct investment. Reflecting the local preferential policies, POL shows a significant negative effect, with the further opening in China. Industrial agglomeration factors can affect to a greater extent than the preferential policies on the location choice of transnational direct investment.

\section{Conclusion}

In this paper, we use the multiple linear regression model to measure and analyze the data and find that the industrial agglomeration factors have replaced the traditional location selection factors as an important force to influence the investment decisions of multinational corporations. It is proven that a preliminary analysis of the foregoing, at this stage of China's economy had developed to a certain level, some industries in some areas have reached a considerable scale, with the leading international enterprises investing in these industries, and the formation of regional industrial agglomeration. At this time, the direct investment which aims to the location of the market growth and the global market for the development strategy of direct investment has increased. Regional industrial agglomeration has become an important factor to attract FDI.

\section{Data sources}

The data source of this paper is 2015 "China Statistical Yearbook" and "China Foreign Economic Statistics Yearbook" in 2015. As the relevant data of some provinces and regions in remotes areas are not complete, and the distribution of FDI is too small, the study excludes data for these provinces in the empirical research. The samples include 23 provinces, autonomous regions and municipalities under the central government.

\section{References}

1. DECD, Main determinants and impacts of foreign direct investment on China' $\mathrm{s}$ economy working papers on international investment, 2000, N0. 40.

2. Y.M. Zhu, the theory of industrial agglomeration, Beijing: Economic Science Press, p27-29 2003.

3. P. Buckley, and M. Casson, The Future of the Multinational Enterprise, London Macmillan,1976.167-172.

4. $J$.H. Dunning, Location and the Multinational Enterprise: A Neglected Factor? Journal of International Business Studie, 1998, No. 29:p45-67. 